\title{
LA REFORMA LEGISLATIVA DE BENEDICTO XVI EN RELACIÓN CON LOS ABUSOS SEXUALES Y ALGUNAS PROPUESTAS PARA LA REFLEXIÓN
}

Fecha de recepción: 16 de septiembre de 2019

Fecha de aceptación y versión final: 22 de octubre de 2019

RESUMEN: Hay quien habla de «estilo Ratzinger» en la lucha contra la pedofilia en la Iglesia. Benedicto XVI afronta el problema y busca la solución, permanece vigilante, endurece la normativa, se encuentra con las víctimas, escucha sus sufrimientos, pide perdón y comparte con ellos las lágrimas. Pide que las Iglesias locales respondan con gestos similares. El «estilo Ratzinger» se concreta en tres aspectos principales: 1) desvelar, manifestar, no ocultar; 2) ejercer la responsabilidad y buscar los mecanismos canónicos que eviten esas situaciones; 3) escuchar, curar, sanar y pedir perdón. Se puede afirmar que con el papa Benedicto XVI la Iglesia hizo los deberes para combatir lo que él denominó «una llaga en el cuerpo de la Iglesia».

PALABRAS CLAVE: Benedicto XVI; abuso sexual; pedofilia; justicia; responsabilidad; perdón.

* Doctor en Teología y en Derecho Canónico: rfelipe@me.com 


\section{The Legislative Reform of Benedict XVI in Relation to Sexual Abuse and some Proposals for Reflection}

ABSTRACT: There are those who talk about «Ratzinger style» in the fight against pedophilia inside the Churh. Benedict XVI faces the problem and searches for solutions, by remaining vigilant, hardening the regulations, meeting the victims, listening to their suffering, asking for forgiveness and sharing their tears. He expects all local churches to enforce the same kind of behaviour. Three main aspects define the «Ratzinger style»: 1) Unveil, expose, refuse to hide; 2) exercise the justice with responsability and find out the canonic ways to avoid these situations; 3) listen, cure, heal and ask for forgiveness. We can say for sure that with Pope Benedict XVI, the Church made their homework in order to fight against the so-called an ulcer in the body of the Church.

KEY WORDS: Benedict XVI; sexual abuse; pedophilia; justice; responsability; forgiveness.

\section{INTRODUCCIÓN}

«Me permito rendir un homenaje al hombre que luchó en momentos que no tenía fuerza para imponerse hasta que logró imponerse: Ratzinger. El Cardenal Ratzinger, sí, un aplauso para él. Es un hombre que tuvo toda la documentación. Siendo Prefecto de la Congregación para la Doctrina de la Fe, tuvo todo en sus manos. Hizo las investigaciones y llegó, y llegó, y llegó... y no pudo ir más allá en la ejecución. Pero, si ustedes se acuerdan, diez días antes de morir San Juan Pablo II, aquel Via Crucis del Viernes Santo, le dijo a toda la Iglesia que había que limpiar las porquerías de la Iglesia. Y en la Misa Pro Eligendo Pontifice, donde no es tonto, él sabía que era candidato, no le importó maquillar su postura, dijo exactamente lo mismo. O sea, fue el valiente que ayudó a tantos a abrir esta puerta» ${ }^{1}$.

El papa Francisco ha definido a Benedicto XVI como «el valiente que ayudó a tantos a abrir esta puerta $»^{2}$. El estudio que presentamos a continuación tiene como finalidad conocer esa "puerta», es decir, el camino que la Iglesia ha emprendido para combatir el delito de abuso sexual a menores cometido por clérigos. Lo haremos buscando conocer cuál ha sido la respuesta eclesial y canónica a los abusos sexuales de menores bajo el impulso de J. Ratzinger, prefecto y papa.

1 Francisco, Conferencia de Prensa, 2. La cita es textual.

2 Ibid. 
El abuso sexual a menores por parte de clérigos es una afrenta a Dios en la acción de la Iglesia y sus sacerdotes. Es un crimen diabólico y criminal. Quien abusa de un menor comete un crimen atroz. El abuso sexual no es solo un pecado y un delito, es también un fenómeno de poder en un ámbito especialmente sensible. Es una traición que rompe el sentido de la confianza. El abuso humilla, castiga, se ensaña mediante la sexualidad. Por ello, todo abuso merece ser atendido, independientemente del momento de su comisión y denuncia. Como afirma Robinson «en el abuso de menores, más que en ninguna otra cosa, es donde se aprende que el sexo no es nunca trivial, porque impacta en lo más profundo del ser de la persona: en el concepto mismo de quién es uno» ${ }^{3}$.

Ha habido errores enormes, silencios dolorosos, traiciones, heridas profundas, vergüenza y deshonor en la reacción, muchas veces, de la Iglesia. Esta, en algunos casos, no ha sabido gestionar el dolor de las víctimas. Se ha acercado con cautela a esas "periferias silenciosas del dolor» y ha reaccionado tarde ante el clamor de las víctimas. No ha sido consciente de que «el impacto del abuso sexual del niño se extiende frecuentemente más allá de la propia víctima hasta alcanzar a otros miembros de la familia o a grupos de amigos» ${ }^{4}$. H. J. Guth señala que la escasa utilización de las normas penales canónicas, observada al inicio de la crisis

«[...] se debe a que, junto a la escasa confianza en la resolución de conflictos mediante la vía judicial eclesiástica en general, también hay un extendido desconocimiento entre los mismos obispos con respecto a las prescripciones del derecho canónico $[\ldots]$ y que, situándose fuera del derecho vigente, catalogan en su mayor parte como "pastorales" sus respuestas a los casos de abuso sexual. Lo que conduce a una ignorancia fatal y a una "tabuización" del problema que, de este modo, sólo contribuye a aumentar el escándalo producido por el abuso sexual $»^{5}$.

Las víctimas han identificado a la Iglesia con su abusador. El clérigo culpable se ha servido de la Iglesia para abusar y esta, en muchos casos, no ha sabido prevenir a tiempo el delito cometido. Las víctimas

\footnotetext{
${ }^{3}$ G. Robinson, Poder y sexualidad (Santander: Sal Terrae, 2008), 204.

4 N. Nason-Clark, y L. Ruff, “¿A qué llamamos violencia sexual?”, Concilium 306 (2004): 369.

5 Hans-Jürgen Guth, "El abuso sexual como delito en el derecho canónico. Informe para una aplicación coherente de las normas jurídicas actualmente vigentes en la Iglesia Católica", Concilium 306 (2004): 466.
} 
sufrieron abusos a manos de un representante de la Iglesia. Por ello exigen que, a través de uno de sus representantes les escuche, reconozca su sufrimiento y ayude a contemplar de nuevo el rostro de Cristo, desfigurado por el pecado. Muchas veces el abuso ha roto también la relación de la víctima con su fe. Se ha oscurecido esa fe porque el culpable era precisamente quien debía iluminarla.

La Iglesia, sin embargo, siempre ha considerado el abuso a menores como un delito. En estos últimos años el esfuerzo normativo para hacer frente al mismo, y a sus nuevas modalidades (pedopornografía) es enorme. A ello ha contribuido el papa Benedicto XVI, ya en su etapa anterior como prefecto de la Congregación para la Doctrina de la Fe.

Como veremos a lo largo de este estudio las pautas marcadas por Benedicto XVI en relación a este delito comprenden los siguientes aspectos: 1) desvelar, manifestar, no ocultar; 2) ejercer la justicia con responsabilidad y buscar los mecanismos canónicos que eviten esas situaciones de nuevo; y 3) escuchar, curar, sanar y pedir perdón.

Para ello se exige, en este campo, una actuación decidida. Esta pasa, necesariamente, por 4 momentos: selección, detección, atención y resolución. Entiendo por selección el periodo que conlleva la preparación al sacerdocio: la selección del candidato y su formación. Es un momento delicado donde se prueba la calidad del candidato junto a la pericia de los formadores. La detección es un momento que conjuga la prudencia con la oportuna decisión. Se trata de estar atento a aquellos indicios que predisponen a una conducta impropia o un delito. Los obispos y superiores, si ejercen como pastores, tienen muchos medios para conocerlos. La vigilancia del pastor no debe entenderse como un "espiar» al otro, sino como una amorosa preocupación por quien depende de él. El obispo se ha obligado a velar por quien ha recibido el Orden de sus manos $^{6}$. El tercer momento importante es la atención. Significa tres cosas: atención, en primer lugar, a la víctima (la persona concreta y toda la Iglesia), atención al delito que deberá investigar de acuerdo con la normativa y, por último, atención al investigado que, culpable o no, tiene sus derechos. Finalmente, el cuarto y último momento le llamo resolución porque conlleva varios aspectos: la resolución del asunto y la sanación de los hechos mediante aquellos medios curativos oportunos. Si las situaciones de impunidad no deben permitirse, tampoco deben serlo las

${ }^{6}$ Cfr. Juan Pablo II, Pastores gregis, 47. 
denuncias no atendidas o atendidas y que duran en el tiempo. Con acierto ha afirmado Arrieta:

«Le risposte della Chiesa in questi anni e le vicissitudini riguardanti la promulgazione e la pubblicazione delle norme mettono in luce, oltre alla delicadezza della materia, i tentennamenti e i dubbi sul modo di affrontare l'insieme delle situazione delittive e scandalose. Modalità non normali di promulgazione di norme, deroghe di principi acquisiti nei sistemi giuridici penali contemporanei, vie non ufficiali di conoscenza di concessione di facoltà speciale in materia penale, lettere circolari che richiedono ulteriori indicazioni per una giusta applicazione, sono elementi che fanno pensare a risposte condizionate dalla frenesia degli eventi. Si tratta di risposte a situazioni di emergenza e perciò è normale che ci siano ripensamenti e modifiche. Non tutto è definitivo e il tempo indicherà se le misure prese in questi anni e le procedure di applicazione sono quelle giuste o se si dovranno modificare. Tempi convulsi non favoriscono norme definitive e perciò la prudenza del Legislatore dovrà essere accentuata nell'ambito della annunciata riforma del libro VI del CIC» ${ }^{7}$.

Pasado el tiempo inicial de la crisis se hace necesario ahora una revisión pausada de la normativa en esta materia, quizás aprovechando la revisión del libro VI del $\mathrm{CIC}^{8}$. Nuestro estudio ofrece también algunas propuestas de cara a esa revisión. Sería deseable que un mayor conocimiento del derecho y su aplicación cure no solo las heridas, sino que genere una mayor confianza en la Iglesia.

La crisis que ha vivido la Iglesia en estos últimos años ha sido ciertamente trágica. Sin embargo, ha puesto al descubierto una realidad terrible que debía ser subsanada. Ha sido un momento de dolor, pero también de renovación. En una conversación con un obispo en cuya diócesis se habían denunciado varios escándalos nos hizo este comentario: «Al ver las denuncias que iban llegando al Obispado recordé el episodio evangélico de la resurrección de Lázaro. Fue necesario levantar la losa, a pesar del olor que pudiera desprenderse, para que llegara Lázaro de nuevo a la vida. No nos importe abrir losas o que las abran. La podredumbre

7 Juan Ignacio Arrieta, "L’influsso del cardinale Ratzinger nella revisione del sistema penale canonico", La Civiltà Cattolica 3851 (2010): 430.

8 Cfr. Juan Ignacio Arrieta, "El proyecto de revisión del libro VI del Código de Derecho Canónico”, Anuario de Derecho Canonico (2013): 212 
que saldrá y que nos hará sufrir, será luego fuente de purificación y de vida». Benditas palabras.

\section{LA TRAGEDIA DE LOS ABUSOS}

Los abusos sexuales a menores, por parte de miembros del clero, son un fenómeno escandaloso, aberrante y convulso. Se trata de un fenómeno complejo que afecta a familias, asociaciones, instituciones educativas, recreativas, culturales y, desgraciadamente, a la misma Iglesia. Hemos tenido acceso a datos impresionantes que afirman que el abuso sexual a menores es un fenómeno "presente en el $60 \%$ de las familias y difundido en todos los ambientes, especialmente en instituciones cerradas ${ }^{9}$. A partir de los estudios que hemos podido consultar, los ámbitos en los que suceden la mayor parte de los abusos se circunscriben a la propia familia (o el entorno), al turismo sexual de menores y a la pornografía infantil. Entre el 10\% y el $20 \%$ de la población infantil han tenido experiencias de abuso sexual en la infancia. Los agresores son, principalmente, miembros de la familia o de su entorno (profesores, tutores, entrenadores $)^{10}$.

Cuando un clérigo abusa sexualmente de un menor, comete una acción moral y canónica del todo reprobable, a la que se añade también un delito. Las consecuencias de todo ello son muy graves: 1) se inflige un daño incalculable al normal desarrollo del menor, a su autoestima y a su dignidad humana; 2) se causa un escándalo tremendo a los fieles y, en general, a la fe; 3 ) constituye invariablemente un abuso y una traición a la confianza sagrada que el Pueblo de Dios tiene en sus pastores; 4) se daña la credibilidad de la Iglesia y es una burla a la belleza de su testimonio para con el Evangelio de Jesucristo que es el camino, la verdad y la vida; 5) se desacredita el ministerio sacerdotal y se coloca a innumerables inocentes bajo la sospecha de la delincuencia, del crimen y del delito ${ }^{11}$.

\footnotetext{
9 Marco Politi, Joseph Ratzinger: crisi di un papato, (Roma 2013), 211.

10 J. M. Pardo, "Abuso a menores. Causas y posibles soluciones", Scripta Theologica 43 (2011): 300.

${ }_{11}$ Cfr. Federico R. Aznar Gil, "Abusos sexuales a menores cometidos por clérigos y religiosos”, REDC 167 (2010): 77. 
Todo abuso sexual, en el marco de la acción pastoral, es una extralimitación, un abuso de confianza y, en virtud del doble desnivel de poder (adulto-niño, sacerdote-fiel), un fenómeno de poder en un ámbito especialmente sensible. Y debe considerarse también como una traición que rompe el sentido de la confianza ${ }^{12}$. El abuso sexual a menores es una derrota de Dios en la acción del pueblo de Dios y sus sacerdotes. Las entrevistas realizadas a la mayoría de sacerdotes abusadores ponen de manifiesto esa experiencia de poder, pues con sus actos lo que pretendían fundamentalmente es humillar, castigar, ensañarse o demostrar su propia masculinidad $^{13}$. La sexualidad es el medio elegido para obtener ese fin ${ }^{14}$.

El hecho de que el abuso sexual se lleve a cabo en medio de una relación pastoral reviste, evidentemente, una gravedad especial. El clérigo se encuentra en una situación de superioridad en relación a la víctima. Este ha acudido en situación de debilidad, de necesidad y ha sido traicionado gravemente. Por un lado es consciente del abuso que ha sufrido, pero por otro lado "no tiene la fuerza de hablar directamente de estos hechos con otras personas, porque lo sentiría como traicionar a quien se preocupa por ella» ${ }^{15}$. Por eso siempre al abuso le sigue el engaño, se busca tranquilizar la conciencia de la víctima con la legitimidad falsa de los actos realizados. Como afirma Robinson,

«Los ofensores no son monstruos que puedan ser identificados como tales a primera vista. Por el contrario, en orden a cometer su ofensa, necesitan poder cautivar a sus víctimas potenciales y ganarse su confianza. Lejos de parecer monstruos, normalmente parecen un pariente o amigo sumamente amable, y pueden ser sacerdotes o religiosos modélicos en todos los demás aspectos de su vida. Ésta es una de las dificultades a la hora de descubrirlos» ${ }^{16}$.

${ }^{12}$ Cfr. Nason-Clark, y Ruff, 366.

13 El poder conlleva responsabilidades. Por eso cuanto mayor es el poder que ejerce la persona, más necesario es el sistema de restricciones antes de utilizarlo y el sistema de rendimiento de cuentas después de haberlo utilizado.

${ }^{14}$ Cfr. Ulrike Brockhaus - Maren Kolshorn, "Die Ursachen sexueller Gewalt", en Sexueller MiBrauch. Überblick zu Forschung. Beratung und Therapie, dir. Gabriele Amann y Rudolf Wipplinger (Tubinga 1998), 91.

15 Damián Astigueta, "La persona y sus derechos en las normas sobre abusos sexuales", Anuario de Derecho Canónico (2004): 18.

16 Robinson, "Poder y sexualidad", 11. 
Las heridas, tras un abuso, son permanentes. No se olvidan fácilmente. Condicionan para siempre la vida. Por eso, en ocasiones, las consecuencias se hacen visibles a lo largo de los años y, también, de manera escalonada. No debe sorprender a la Iglesia recibir denuncias de hechos acontecidos muchos años antes y mucho menos deben ser tenidas en cuenta como secundarias. Todo abuso merece ser atendido, independientemente del momento de su comisión y denuncia. Los delitos llamados históricos merecen toda consideración.

\section{LA REFORMA DE BENEDICTO XVI}

El gobierno «gentil» de Benedicto XVI tomó decisiones muy importantes para eliminar lo que él denominó la «suciedad» en la Iglesia ${ }^{17}$. No solo se sirvió de su experiencia en la Congregación para la Doctrina de la $\mathrm{Fe}$, sino que promovió grandes reformas y no dudó en tomar decisiones de gobierno que implicaron el cese y la dimisión del estado clerical de sacerdotes y obispos ${ }^{18}$. La forma normativa que dió a esa reforma ha ayudado a prevenir el abuso y a satisfacer, si es posible, el escándalo causado en la Iglesia y en la sociedad.

\subsection{UNA PREOCUPACIÓN SIEMPRE PRESENTE}

Con motivo de la revisión del sistema penal canónico, que se está llevando a cabo en la actualidad, se dió a conocer una carta interesantísima, fechada el 19 de febrero de 1988. Afirma mons. Arrieta que «se trata de un documento importante y único, en el que se ponen de relieve las

17 Dijo J. Ratzinger durante el Via Crucis: «¡Cuánta suciedad en la Iglesia y entre los que, por su sacerdocio, deberían estar entregados al Redentor! ¡Cuánta soberbia! La traición de los discípulos es el mayor dolor de Jesús. No nos queda más que gritarle: Kyrie, eleison. Señor, sálvanos»; "La pederastia, la cruz del Pontificado de Ratzinger", El Mundo, visitado el 3 de mayo de 2018, http://www.elmundo.es/elmundo/2010/03/22/internacional/1269282454.html.

18 Según Hans Zollner, director del Centro para la prevención del menor de la Universidad Gregoriana, el papa Benedicto XVI dimitió del estado clerical a más de 400 sacerdotes en los dos últimos años de su pontificado; cfr. "Entrevista a H. Zollner", Aleteia, visitado el 3 de mayo de 2018, http://es.aleteia.org/2014/02/15/pedofiliavaticano-experto-en-defensa-de-los-menores-responde-a-las-acusaciones-de-la-onu/ 
consecuencias negativas para la Iglesia causadas por algunas opciones del sistema penal establecido apenas cinco años antes» ${ }^{19}$. Escribe la carta el entonces prefecto de la CDF, el cardenal Joseph Ratzinger, al presidente de la denominada en ese momento PCITL ${ }^{20}$. El texto dice así:

«Eminencia, este dicasterio, al examinar las peticiones de dispensa de los compromisos sacerdotales, encuentra casos de sacerdotes que, durante el ejercicio de su ministerio, se han hecho culpables de graves y escandalosos comportamientos, para los cuales el CIC, previo adecuado procedimiento, prevé la irrogación de sanciones concretas, sin excluir la reducción al estado laical. A juicio de este dicasterio, dichas medidas, por el bien de los fieles, deberían ser anteriores, en algunos casos, a la eventual concesión de la dispensa sacerdotal que, por su propia naturaleza, se configura como una "gracia" en favor del orador. Sin embargo, dada la complejidad del procedimiento previsto a este propósito por el Código, es previsible que algunos Ordinarios encuentren muchas dificultades para realizarlo. Agradeceré por tanto a Vuestra Eminencia Reverendísima si pudiera hacer conocer su estimado parecer sobre la eventual posibilidad de prever, en casos determinados, un procedimiento más rápido y simplificado» ${ }^{21}$.

El motivo de la carta está bien delimitado. La CDF era por entonces competente para estudiar las peticiones de dispensa de las obligaciones sacerdotales asumidas con la ordenación ${ }^{22}$. La concesión de dicha dispensa era un maternal gesto de gracia por parte de la Iglesia, después de haber examinado atentamente, por un lado, el conjunto de todas las circunstancias que concurrían en el caso concreto, y de haber ponderado, por otro, la objetiva gravedad de los compromisos que se habían asumido ante Dios y la Iglesia en la ordenación sacerdotal. Las circunstancias que motivaban algunas de estas peticiones de dispensa de estos compromisos, sin embargo, no eran en modo alguno meritorias de actos de gracia. ¿Qué dice exactamente la carta del cardenal Ratzinger? El objetivo de la carta es doble. Por un lado, manifestar la «repugnancia» de conceder un "acto de gracia» (dispensa de las obligaciones sacerdotales) a quien, por sus graves delitos, es necesario imponer un castigo (dimisión ex poena del estado clerical). Por otro lado, ponía de manifiesto que, aunque el

\footnotetext{
19 Arrieta, "L'influsso del cardinale Ratzinger", 431.

20 Posteriormente PCTL.

21 Arrieta, "L'influsso del cardinale Ratzinger", 435.

${ }^{22}$ Benedicto XVI trasladó esta competencia a la Congregación del Clero.
} 
código reconocía la existencia de una jurisdicción específica de la CDF en materia penal (CIC c. 1362 §1.1), no era en cambio evidente en el contexto normativo qué delitos concretos pudiesen estar comprendidos en las competencias penales del dicasterio. Es decir, para el card. Ratzinger era imprescindible recordar la grave responsabilidad jurídica en materia penal que corresponde a los ordinarios y superiores religiosos.

La respuesta de la PCITL llegó tres semanas después. Y dice así:

«Entiendo bien la preocupación de Vuestra Eminencia de que los correspondientes Ordinarios no hayan ejercido antes su potestad judicial para castigar adecuadamente, también como tutela del bien común de los fieles, dichos delitos. Sin embargo, el problema no parece ser de procedimiento jurídico sino del ejercicio responsable de la función de gobierno. En el Código vigente han sido determinados claramente los delitos que pueden comportar la pérdida del estado clerical: éstos han sido configurados en los cann. 1364 § 1, 1367, 1370, 1387,1394 y 1395 . Al mismo tiempo, se ha simplificado mucho el procedimiento respecto a las precedentes normas del CIC 1917, haciéndolo más rápido y sencillo, también con la finalidad de impulsar a los Ordinarios al ejercicio de su autoridad, mediante el necesario juicio de los culpables "ad normam iuris" y la aplicación de las sanciones previstas. Tratar de simplificar ulteriormente el procedimiento judicial para infligir o declarar sanciones tan graves como la dimisión del estado clerical, o bien cambiar la actual norma del 1342 § 2, que prohíbe proceder en estos casos mediante decreto administrativo extrajudicial (cfr. can. 1720), no parece en absoluto conveniente. En efecto, por un lado se pondría en peligro el derecho fundamental a la defensa - en causas que conciernen al estado de la persona-, mientras que, por otro, se favorecería la deplorable tendencia - quizás por falta del debido conocimiento o estima por el derecho- a un equívoco gobierno, denominado "pastoral", que en el fondo no es pastoral, porque lleva a descuidar el debido ejercicio de la autoridad, dañando el bien común de los fieles. También en otros períodos difíciles de la vida de la Iglesia, de confusión de las conciencias y de relajamiento de la disciplina eclesiástica, los sagrados Pastores no han dejado de ejercer su potestad judicial, para tutelar el bien supremo de la "salus animarum". Teniendo en cuenta todo esto esta Pontificia Comisión opina que se debe insistir oportunamente ante los Obispos (cfr. can. 1389) para que, cada vez que sea necesario, no dejen de ejercer su potestad judicial y coactiva, en lugar de enviar a la Santa Sede las peticiones de dispensa ${ }^{23}$.

23 Arrieta, "L'influsso del cardinale Ratzinger", 438. 
La respuesta de la PCITL se centra básicamente en tres aspectos. En primer lugar, se pone de manifiesto algo que parece obvio. El «problema» no es tanto de procedimiento jurídico sino de un ejercicio responsable de la autoridad. Algo que parece probado al analizar multitud de casos de denuncias y las omisiones clamorosas en su resolución. En segundo lugar, se verifica la necesidad de impulsar en los ordinarios el ejercicio de su autoridad mediante el necesario juicio de los culpables ad normam iuris y la aplicación de las sanciones previstas. Es decir, se trata de aplicar los procedimientos que la legislación prevé para los casos de abusos que conllevan sanciones determinadas. Hay que recordar que, en este sentido, la normativa codicial del momento es muy clara, y que las normas que fueron añadiéndose a medida que surgían los escándalos no hacen más que incidir en esa urgencia de aplicarlas. Es importante destacar que, con posterioridad a estas cartas, se producen algunas actuaciones del papa san Juan Pablo II, fruto de los desvelos de la CDF y, en consecuencia, del cardenal Ratzinger ${ }^{24}$. En tercer lugar, la PCITL recuerda que descuidar el ejercicio de la autoridad daña el bien común de los fieles. Ciertamente, y no deberíamos nunca dejar de insistir en ello, se lesionan los derechos de los fieles cuando se margina este ejercicio o se actúa con grave negligencia. Hay que reconocer que algunas actuaciones, por ejemplo, de la Iglesia en EE. UU., no ayudaron en nada a defender los derechos de los fieles. Más bien, oscurecieron ese derecho y causaron un grave daño a la Iglesia.

La carta del card. Ratzinger, dada a conocer por mons. Arrieta, pone de manifiesto, una vez más, la coherencia del entonces cardenal en su lucha contra este delito y el escándalo que le causaba comprobar cómo la disciplina universal en esta materia, por otro lado muy clara en el CIC, no era aplicada en infinidad de casos. La normativa posterior, tanto del papa san Juan Pablo II, como de la CDF, obedece, sin duda, a los desvelos del cardenal ${ }^{25}$. Desde ahora la actuación de J. Ratzinger, primero

${ }^{24}$ Por ejemplo, el Rescripto ex audientia de junio de 1994, la carta que un año antes envió el papa a los obispos de EE. UU. o las reuniones con los cardenales norteamericanos para analizar la situación surgida tras la crisis.

${ }^{25}$ El papa san Juan Pablo II, al tomar conciencia de la gravedad del asunto, no solo promovió la reforma ad casum de la prescripción para EE. UU., sino también pronunció las palabras que abrieron su lucha contra los abusos en la Iglesia y centraron la tolerancia cero que han seguido los Pontífices posteriores: «Las personas tienen que saber que no hay lugar en el sacerdocio y en la vida religiosa para quienes hacen daño a los jóvenes», Discurso a los cardenales de EE. UU., 4. 
como prefecto y posteriormente como papa, girará en torno a la preocupación ante la gravedad de los hechos, el escándalo ante la impunidad con la que se responde y la urgente necesidad de un ejercicio responsable de la autoridad. Bajo estos tres ejes, Benedicto XVI centrará posteriormente su trabajo en esta materia.

\subsection{UNA ELABORACIÓN CONTÍNUA}

A lo largo del pontificado del papa Benedicto XVI (y en su anterior etapa como prefecto de la CDF) se producen importantes reformas legislativas, actuaciones pastorales y disciplinares que abordan la crisis de los abusos desde diferentes aspectos. Hay que mencionar, en primer lugar, el m. p. Sacramentorum sanctitatis tutela (SST), la Carta Circular a las Conferencias Episcopales que contiene las Líneas Guía de actuación ante estos delitos y las especiales concesiones, en esta materia, a la CCL.

SST fue promulgado por el papa san Juan Pablo II el 30 de abril de 2001 y trata sobre los delitos más graves reservados a la CDF. Como afirma el cardenal Levada:

«[...] bajo la cuidadosa dirección del entonces Prefecto de la Congregación para la Doctrina de la Fe, el cardenal Ratzinger, la Santa Sede consiguió garantizar que se diera una respuesta coordinada al creciente número de informes relativos a abusos sexuales y que se abordaran de manera efectiva los correspondientes aspectos canónicos, incluyendo el recurso contra las decisiones de los Obispos y Superiores Mayores ${ }^{26}$.

Se trata de una ley especial donde se incluyen en la lista de los delitos más graves, reservada a la $\mathrm{CDF}$, los abusos sexuales contra menores de 18 años cometidos por clérigos. Afirma Sánchez-Girón: «Las normas de 2001 pretendían responder a lo previsto en el artículo 52 de Pastor Bonus. En él se dice que la CDF conoce los delitos contra la fe y los más graves contra la moral y los sacramentos, pero no especifica cuáles son y era preciso hacerlo» ${ }^{27}$. Lo cierto es que, hasta el momento, además del art. 52 de Pastor Bonus, existían únicamente algunas normas codiciales

\footnotetext{
${ }^{26}$ William Levada, "El abuso sexual contra menores: una respuesta polifacética al reto", en Abuso sexual contra menores, dir. Charles Scicluna, Hans Zollner y Daniel Ayotte (Santander: Sal Terrae, 2012), 26.

27 José Luis Sánchez-Girón Renedo, "Delitos contemplados en las normas De gravioribus delictis del año 2010”, Estudios Eclesiásticos 85 (2010): 733.
} 
que se referían a los delitos reservados a la CDF. Se trata del c. 1362.1 del CIC y el c. 1152 del CCEO, que excluían del plazo común de prescripción, aquellos delitos reservados a la CDF. Existía esa "presunción» de la existencia de delitos reservados a la CDF, pero aún no se habían establecido cuáles eran. Posteriormente el 21 de mayo de 2010 la CDF daba a conocer unas modificaciones a las normas sustanciales y procesales del m. p. SST, aprobadas por el papa Benedicto XVI. El 15 de julio de 2010, mediante su publicación en el sitio de internet de la Santa Sede, se conocieron dichas modificaciones ${ }^{28}$.

Afirma también el cardenal Levada, entonces prefecto de la CDF:

«Nueve años después de que se introdujera el Sacramentorum sanctitatis tutela, y a la luz de la experiencia recabada al abordar los miles de casos que se han presentado desde distintos lugares del mundo, la CDF presentó al Santo Padre una serie de propuestas de modificación de la legislación adoptada en 2001. Las líneas esenciales del SST no sufrieron modificaciones, aunque sí se enmendaron algunas normas sustanciales y procesales, en un esfuerzo por conseguir que la ley permitiera lidiar de forma más eficaz con la complejidad inherente a estos casos. El Papa Benedicto XVI aprobó y ordenó que se promulgaran las normas revisadas el 21 de mayo de 2010.

Algunas de las principales aportaciones con respecto a la legislación precedente implican la consolidación de prácticas que habían recibido previamente el reconocimiento y la aprobación de los Papas san Juan Pablo II y Benedicto XVI, como el derecho a derogar el plazo de prescripción de estos delitos; la facultad de dispensar de la vía procesal judicial para permitir el recurso a la extrajudicial (administrativa)

${ }^{28}$ Además de presentar las modificaciones en el sitio web de la Santa Sede, se incorporaron cuatro documentos, a saber, la Carta a los Obispos de la Iglesia Católica y a los Ordinarios y Jerarcas interesados acerca de las modificaciones introducidas en la Carta apostólica 'motu proprio data' Sacramentorum sanctitatis tutela, en cinco idiomas, de 21 de mayo, firmada por el Prefecto y el Secretario de la CDF. Acompaña a esta carta una "Relación", en seis idiomas, que enumera las modificaciones introducidas en el nuevo texto de las Normas. Los documentos restantes son una "Introducción histórica a cargo de la CDF" en tres idiomas, que ilustra la evolución de esta normativa desde el Código de 1917 y, finalmente, una Nota del P. Federico Lombardi, director de la OPSS, que lleva por título El significado de la publicación de las nuevas Normas sobre los delitos más graves, en cinco idiomas. Cabría plantearse el porqué de unas modificaciones tan solo nueve años después de la publicación del m. p. SST. Es evidente que hay una serie de causas objetivas que podríamos resumir en las siguientes: la gravedad del problema de los abusos, la experiencia de la CDF y las dificultades encontradas, la insistencia de algunos medios de comunicación, etc. 
en aquellos casos en que los hechos parecen evidentes; la facultad de presentar los casos de extrema gravedad directamente ante el Santo Padre para la expulsión del estado clerical; la inclusión del delito de posesión y/o distribución de pornografía infantil (en el caso de menores de 14 años); y otras especificaciones sobre delitos contra la Eucaristía y el sacramento de la Penitencia, así como un delito contra el sacramento del Orden sacerdotal» ${ }^{29}$.

El documento se presenta ahora compuesto por 31 artículos respecto a los 26 de la primera edición. No deja de sorprender, de entrada, la modalidad de la publicación de estas normas, teniendo en cuenta la estricta reserva que ha caracterizado siempre la actuación de la CDF en estas materias. Incluso, algunos, han hablado de un cierto "secretismo» ${ }^{30}$ o también «perplejidad» acerca de esta modalidad de promulgación ${ }^{31}$. Junto a la presentación de estas modificaciones, se recogieron otro tipo de documentos que tenían por objeto ofrecer a la opinión pública las líneas de actuación sobre las cuales la Iglesia se mueve en este campo. Como afirmó el P. Lombardi: «es justo que haya claridad plena sobre la normativa actualmente en vigor en este ámbito y que dicha normativa se presente de forma orgánica para facilitar así la orientación de todos los que se ocupen de estas materias ${ }^{32}$.

\subsection{OTRAS INTERVENCIONES LEGISLATIVAS}

Tras la publicación de SST y sus modificaciones, la CDF envió a todas las Conferencias Episcopales una Carta circular para ayudar a las Conferencias Episcopales en la preparación de Líneas guía para tratar los

29 Levada, 28.

${ }^{30}$ Cfr. Kurt Martens, "Les délits les plus graves réservés à la Congrégation pour la Doctrina de la Foi", Revue de Droit Canonique 56 (2006): 218. Contrasta la manera de presentar estas normas, con lo ocurrido con la instrucción Crimen sollicitationis. En el subtítulo de la misma se puede leer: «servanda diligenter in archivo secreto curiae pro norma interna non publicanda nec ullis commentariis augenda»; cfr. SSCSO, Crimen sollicitationis, Parte preliminar.

31 Cfr. Davide Cito, "Las nuevas normas sobre los delicta graviora", Ius Canonicum 50 (2010): 648.

32 "El significado de la publicación de las nuevas Normas sobre los delitos más graves", Federico Lombardi, visitado el 6 de mayo de 2015, http://www.vatican.va/ resources/resources_lombardi-nota-norme_sp.html. 
casos de abuso sexual de menores por parte del clero. La preparación del documento había sido anunciada en julio de 2010, con ocasión de la publicación de las nuevas normas de actuación del m. p. SST ${ }^{33}$. Monseñor Levada, prefecto entonces de la CDF, había informado sobre la preparación de estas Líneas Guía durante el Consistorio de cardenales de noviembre de 2010.

$\mathrm{Al}$ documento le acompaña una carta de presentación, firmada por el mismo cardenal Levada, que explica básicamente la naturaleza y los objetivos que se pretenden. Como consecuencia de la actualización de las normas sobre los abusos sexuales por parte de miembros del clero, aprobada como hemos visto, por el papa Benedicto XVI el 21 de mayo de 2010, se consideró «oportuno que cada Conferencia Episcopal prepare unas Líneas guía», con el fin de "ayudar a los Obispos a seguir procedimientos claros y coordinados cuando se tienen que tratar los casos de abusos sexuales contra menores», teniendo en cuenta las situaciones concretas de las diversas regiones del mundo ${ }^{34}$. Se pide, en la misma carta de presentación, que se envíe un ejemplar completo de las Líneas guía a la CDF antes de fin de mayo de $2012^{35}$.

${ }^{33}$ Cfr. Federico Lombardi, "Nota sulla lettera circolare della Congregazione per la Dottrina della Fede alle Conferenze Episcopali”, La Civiltà Cattolica 3864 (2011): 594-597.

34 En relación a la acogida de esta carta es interesante lo que afirma Zollner: «Por desgracia algunas Conferencias Episcopales, especialmente del África francófona, no han respondido aún. En muchos países en donde existe una guerra o hay catástrofes naturales es difícil hablar de líneas guía de este tipo. En algunas zonas del mundo existe mucha resistencia a hablar del argumento, no sólo en la Iglesia sino en toda la sociedad, por lo que es difícil tener líneas guía en estas Conferencias, pero la mayoría — aproximadamente el 90\% — han respondido; reciben indicaciones por parte de la Congregación para la Doctrina de la Fe, y luego deben efectuar los procedimientos»; cfr. "Entrevista a H. Zollner", Aleteia, visitado el 3 de mayo de 2018, http:// es.aleteia.org/2014/02/15/pedofiliavaticano-experto-en-defensa-de-los-menores-responde-a-las-acusaciones-de-la-onu/

35 El P. Lombardi, en la presentación de esta carta circular afirmó que las Líneas guía subrayan la responsabilidad de los obispos o de los superiores mayores religiosos, que pueden recibir ayuda de expertos, pero a condición de que esta no suponga abdicar a la responsabilidad específica que tiene el superior. El portavoz vaticano explicó que, en los países de lengua inglesa, en general, las conferencias ya habían asumido líneas de respuesta a estos casos, en particular en EE. UU., Irlanda, Inglaterra y Gales, Escocia, Nueva Zelanda, Malta, Australia, y Canadá. En Asia, los obispos de Filipinas ya habían adoptado Líneas guía, mientras que los de la India estaban trabajando en estos momentos en la redacción del documento. En América Latina, Brasil y Chile ya habían 
La CDF ofrece, en esta carta circular, una amplia serie de principios e indicaciones, que no solo facilitan la formulación de las Líneas guía y, por tanto, la uniformidad de la conducta de las autoridades eclesiásticas en las diferentes naciones, sino que también garantizan la coherencia en el nivel de Iglesia universal, aun respetando las competencias de los obispos y de los superiores religiosos. La atención prioritaria a las víctimas, los programas de prevención, la formación de los seminaristas y la formación permanente del clero, la cooperación con las autoridades civiles, la aplicación atenta, unitaria y rigurosa de la normativa canónica más actualizada en esta materia son las orientaciones principales que deben constituir las directrices en todo el mundo ${ }^{36}$.

El 30 de enero de 2009 el papa Benedicto XVI concedía a la CCL «facultades especiales» para la dimisión del estado clerical, por la comisión de algunos delitos, mediante un procedimiento administrativo ${ }^{37}$. Las razones que motivan esta especial concesión giran, principalmente, en torno a la necesidad de tutelar la honestidad de vida de los clérigos ${ }^{38}$. La carta mediante la cual se presentan estas normas hace mención a la petición de algunos ordinarios a la Santa Sede para que se flexibilice el sistema que permita intervenir, con eficacia y autoridad, en determinados casos, contando con la confirmación de las actuaciones por parte del dicasterio correspondiente ${ }^{39}$.

adoptado este tipo de medidas, mientras que lo estaban haciendo en estos momentos en la Conferencia Episcopal de Venezuela. Por lo que se refiere a Europa, las Líneas guía de Alemania eran muy conocidas y ya se habían adoptado en Austria, Suiza, Eslovenia y Francia, y se están trabajando en Holanda, Suecia y Bélgica.

36 CDF, Lettera circolare, 588.

37 El 3 de marzo de 1997 san Juan Pablo II había concedido a la CEP la facultad especial de obtener la dimisión del estado clerical, con dispensa de todas las obligaciones de la ordenación, incluída la dispensa del celibato, para todos los sacerdotes incardinados en circunscripciones eclesiásticas de territorios dependientes de dicho dicasterio, responsables de graves delitos contra el sexto mandamiento, de acuerdo con el c. 1395; cfr. V. Mosca, "Le facoltà speciali concesse alla Congregazione per l'Evangelizzazione dei Popoli e alla Congregazione per il Clero (in particolare circa la dimissione dalla condizione giuridica clericale in poenam ed ex officio per via amministrativa)", Quaderni de ius missionale 3 (2014): 159-180.

38 Cfr. Federico R. Aznar Gil, "La expulsión del estado clerical por procedimiento administrativo", REDC 168 (2010): 257.

${ }^{39}$ Cfr. Marek Golab, "Facultades especiales para la dimisión del estado clerical (Congregación para el Clero de 30 de enero de 2009). Análisis y comentario", Ius Canonicum 50 (2010): 672. 
Las facultades especiales indican el procedimiento administrativo a seguir para proceder a la expulsión del estado clerical a aquellos que han realizado «situaciones de grave indisciplina [...] en las cuáles todo esfuerzo por resolver el problema con medios pastorales y canónicos, previstos ya en el Código de Derecho Canónico, no sean suficientes e idóneos para reparar el escándalo, restablecer la justícia y hacer que el reo se enmiende» ${ }^{40}$.

\subsection{UNA PREOCUPACIÓN UNIVERSAL}

Tras los EE. UU., una de las crisis más grandes relativas al abuso de menores por parte de clérigos es la producida en Irlanda ${ }^{41}$. No solo por el enorme daño causado, sobre todo a las víctimas y a toda la Iglesia, sino también por las intervenciones del Gobierno irlandés y de la Iglesia católica, principalmente del papa Benedicto XVI. Decía el papa Benedicto XVI a los obispos de Irlanda, en visita ad limina, el 28 de octubre de 2006:

«En el ejercicio de vuestro ministerio pastoral, durante los últimos años habéis tenido que responder a muchos casos dolorosos de abuso sexual de menores. Son mucho más trágicos cuando el pederasta es un clérigo. Las heridas causadas por estos actos son profundas, y es urgente reconstruir la confianza donde ha sido dañada. En vuestros continuos esfuerzos por afrontar de modo eficaz este problema, es importante establecer la verdad de lo sucedido en el pasado, dar todos los pasos necesarios para evitar que se repita, garantizar que se respeten plenamente los principios de justicia y, sobre todo, curar a las víctimas y a todos los afectados por esos crímenes abominables. De este modo, la Iglesia en Irlanda se fortalecerá y podrá dar un testimonio más eficaz de la fuerza redentora de la cruz de Cristo. Ruego para que, por la gracia del Espíritu Santo, este tiempo de purificación permita

40 Ibid, 672 .

${ }^{41}$ Con motivo de la Cuaresma de 2005, los obispos de Irlanda publicaron una carta pastoral que lleva por título Hacia la curación. Reflexión de Cuaresma. En ella, conscientes de la gravedad del problema, ofrecen diferentes consideraciones. Los temas principales son: la incredulidad inicial ante los abusos, el derecho a la buena fama, las respuestas insuficientes de la autoridad, el acercamiento a las víctimas principales y secundarias (familiares, compañeros) y la necesidad de curación; cfr. Obispos de Irlanda, "Hacia la curación. Reflexión de Cuaresma”, Documentation Catholique 2334 (2011): 388-394. 
a todo el pueblo de Dios en Irlanda "conservar y llevar a plenitud en su vida la santidad que recibieron" (Lumen gentium, 40). La excelente labor y la entrega desinteresada de la gran mayoría de los sacerdotes y los religiosos en Irlanda no deben quedar oscurecidas por las transgresiones de algunos de sus hermanos. Estoy seguro de que la gente lo entiende, y sigue sintiendo afecto y estima por su clero. Animad a vuestros sacerdotes a buscar siempre la renovación espiritual y a redescubrir la alegría de apacentar su grey dentro de la gran familia de la Iglesia ${ }^{42}$.

Existe también una respuesta por parte de la Santa Sede al llamado Cloyne Report, informe minucioso sobre los abusos en la diócesis de Cloyne ${ }^{43}$. Y la carta del papa Benedicto XVI a los católicos de Irlanda. Esta carta supone un hito en la lucha contra la pederastia en la Iglesia y un aviso a los pastores que la negligencia en esta materia traerá también consecuencias personales. La destitución de algunos significativos obispos en Irlanda es un ejemplo. Además tuvieron lugar diferentes reuniones de los obispos de Irlanda con el papa y diferentes organismos de la Santa Sede, visitas apostólicas, alocuciones y homilías del santo Padre como actos de perdón y reparación y también decisiones disciplinares: ceses, renuncias, etc ${ }^{44}$. Para D. Cito,

«[...] es a partir del informe Murphy [...] cuando el Santo Padre ha emprendido más directamente una acción espiritual, pastoral y jurídica para ayudar a la Iglesia no sólo a desarrollar una nueva sensibi-

${ }^{42}$ Benedicto XVI, "A los Obispos de Irlanda en visita ad limina”, 28 de octubre de 2006, visitado el 2 de mayo de 2018, http://www.vatican.va/resources/resources_adlimina-irish-bishops-oct2006_sp.html.

43 Cfr. Informe Cloyne, Il Regno 19 (2011): 593.

${ }^{44}$ La Conferencia Episcopal Irlandesa ya había publicado en los años 1996 y 2003 sendos documentos de diferente valor doctrinal, que pretendían dar una respuesta adecuada y común a la crisis de los abusos, estableciendo normas de actuación para responder adecuada y coordinadamente a estas situaciones delictivas. Estos documentos llevan por título: "Child Sexual Abuse: framework for a Church Response" y "Our Children, our Church. Child protection policies and procedures for the Catholic Church in Ireland”. Posteriormente, en el año 2009, se publicó otro documento, de mayor alcance, que lleva por título "Salvaguardar a los niños. Documento de normas y guía para la Iglesia Católica en Irlanda”. Este a cargo del National Board for Safeguarding Children in the Catholic Church. Pueden consultarse estos documentos en www.catholicbishops.ie. 
lidad hacia el problema de los abusos de menores, sino también para ofrecer criterios orientadores con vistas a la acción de los Pastores ${ }^{45}$.

La Carta a los católicos de Irlanda tiene palabras concretas para, en primer lugar, las víctimas de abusos y sus familias, los sacerdotes y religiosos que han abusado de niños, los padres, los niños y jóvenes, los obispos y todos los fieles de Irlanda. A las víctimas de abusos y a sus familias el papa se acerca desde «la vergüenza y el remordimiento que sentimos todos» (n. ${ }^{\circ}$ 6). Reconoce el sufrimiento inmenso de las víctimas, la confianza traicionada y el silencio con que se recibieron, en muchos casos, sus denuncias. Les invita a acercarse de nuevo a Cristo «que entiende la profundidad de vuestro dolor y la persistencia de su efecto en vuestra vida y en vuestras relaciones con los demás, incluyendo vuestra relación con la Iglesia» (n. ${ }^{\circ}$ 6). A los sacerdotes y religiosos que han abusado de niños les recuerda la traición que han cometido, el inmenso daño causado a las víctimas y el daño enorme a la Iglesia. Les pide «asumir la responsabilidad de los pecados que habéis cometido y a expresar con humildad vuestro pesar» (n. $\left.{ }^{\circ} 7\right)$. Y añade el papa: «Admitid abiertamente vuestra culpa, someteos a las exigencias de la justícia, pero no desesperéis de la misericordia de Dios» (n. ${ }^{\circ} 7$ ). A los padres les invita a trabajar por "garantizar a los niños los mejores cuidados posibles, tanto en el hogar como en la sociedad en general» (n. $\left.{ }^{\circ} 8\right)$, mientras les asegura que la Iglesia no va a dejar de aplicar cuantas medidas sean necesarias para proteger a los niños y jóvenes en los ambientes parroquiales y escolares. A estos, el papa les invita a encontrar a Jesucristo en la Iglesia y a buscar una relación personal con Él, mediante la oración y los sacramentos ${ }^{46}$. A los sacerdotes y religiosos de Irlanda, el papa les reconoce el sufrimiento, la decepción por el escándalo de sus hermanos, y también la entrega de su vida sacerdotal y religiosa. Les pide que sean hombres y mujeres de oración y que vivan, con valentía, el camino de la conversión, la purificación y la reconciliación. A los obispos, el papa les dirige palabras claras y contundentes. Les recuerda que han fallado «a veces gravemente» cuando debían aplicar el derecho y oir a las víctimas, que han cometido "graves errores en la respuesta a las acusaciones» y que, con su actuación, "han socavado gravemente» la credibilidad de la Iglesia (n. $\left.{ }^{\circ} 11\right)$. Y les exige: honradez y transparencia, colaboración con

${ }^{45}$ Cito, "Las nuevas normas", 648.

${ }^{46}$ Cfr. Benedicto XVI, Carta a los católicos de Irlanda, 9. 
las autoridades civiles, aplicar plena e incondicionalmente las normas de la Iglesia para la protección de los niños y jóvenes y que trabajen por la purificación interna y la renovación espiritual de la Iglesia en Irlanda.

A todos los fieles de Irlanda, el papa les pide «aspirar a altos ideales de santidad, caridad y verdad» (n. $\left.{ }^{\circ} 12\right)$. La carta acaba anunciando una visita apostólica a algunas diócesis de Irlanda y a los seminarios y congregaciones religiosas. El objetivo es ayudar a las iglesias locales en el camino de renovación que propone el papa en su carta ${ }^{47}$. Y también una gran misión, a nivel nacional, para todos los obispos, sacerdotes y religiosos, que pretende «redescubrir las raíces de vuestra fe en Jesucristo y de beber en abundancia en las fuentes de agua viva que os ofrece a través de su Iglesia» (n. $\left.{ }^{\circ} 13\right)$.

El 20 de marzo de 2012 la Santa Sede hizo públicos los resultados de la visita apostólica a Irlanda, anunciada por el papa en su carta anterior $^{48}$. Se trata de una síntesis de las conclusiones de las visitas a las cuatro archidiócesis, a los institutos religiosos y a los seminarios irlandeses. El texto incluye también algunas indicaciones de la Santa Sede, que se suman a las que los diversos dicasterios enviaron a los responsables de las instituciones visitadas. Resumimos, a continuación, los principales contenidos de esta nota: 1) se reafirma la consternación del papa, expresada en la Carta a los católicos de Irlanda y la cercanía, manifestada en diversas ocasiones, a todas las víctimas; 2) la visita ha servido para constatar, una vez más, la gravedad de los hechos y la necesidad de acoger y asistir a todas las víctimas de los abusos; 3 ) recordar las directrices ya vigentes para la Iglesia de Irlanda y que se concretan en los siguientes puntos: participación generalizada de los fieles en el trabajo de prevención y de formación, la estrecha colaboración con las autoridades civiles y la referencia a la CDF de aquellas materias que están bajo su

47 Ibid., 13.

${ }^{48}$ La Secretaría de Estado, de la Santa Sede, explicaba más ampliamente la naturaleza pastoral de esta visita que pretende, básicamente, estas finalidades: identificar si existe una mutua relación entre los diferentes componentes de la Iglesia local para realizar el camino de profunda renovación espiritual ya iniciado por la Iglesia en Irlanda; verificar la efectividad del actual procedimiento empleado para responder a los casos de abuso y de las usuales formas de asistencia previstas para las víctimas, aclarando que no se pretendía hacer una investigación de casos individuales de abuso ni un proceso para juzgar hechos pasados; y, finalmente, identificar problemas explícitos que puedan requerir alguna asistencia de la Santa Sede; cfr. SE, Nota respiciens, 924-28. 
competencia. La Santa Sede pide actualizar estas normas, de acuerdo a las publicadas por la CDF el 3 de mayo de 2011 y que son revisadas periódicamente; 4) necesidad de elaborar una normativa para algunos casos concretos. Estos son: aquellos en los que el sacerdote o religioso ha sido acusado, pero el fiscal ha decidido no proceder; establecer normas para facilitar el regreso al ministerio de los sacerdotes acusados falsamente y, finalmente, proporcionar adecuada atención pastoral a los sacerdotes o religiosos que hayan sido declarados culpables de abuso de menores; 5) en relación a los seminarios, además de insistir en aquellos aspectos básicos de la formación humana, espiritual y pastoral de los futuros sacerdotes, se pide también incluir en el historial académico una formación profunda en la tutela de los menores.

Benedicto XVI se tomó muy en serio la problemática de Irlanda, que le causó una especial preocupación ${ }^{49}$. En la visita apostólica del papa Benedicto XVI al Reino Unido, que tuvo lugar en el mes de septiembre de 2010, son varias las intervenciones del pontífice en relación a los

49 Benedicto XVI se refirió a la situación de Irlanda en estos términos: «Desde mi elección a la sede de Pedro me había encontrado ya varias veces con víctimas de abuso sexual. Tres años y medio antes, en octubre de 2006, había exigido en mi discurso a los obispos de Irlanda sacar a la luz la verdad, hacer todo lo necesario para que no se repitan crímenes tan tremendos, garantizar que se respeten los principios del derecho y la justicia y, sobre todo, curar a las víctimas [...]. Después de que el informe Ryan pusiese al descubierto la enorme magnitud del abuso sexual también en Irlanda, la Iglesia se encontró en un nuevo país frente a un montón de añicos. "Llevará generaciones repararlo". Lo dijo el religioso irlandés Vicent Twomey. En Irlanda el problema se plantea de forma muy específica: "allá existe una sociedad católica, por así decirlo, cerrada, que permaneció siempre fiel a su fe católica a pesar de una opresión de siglos, pero en la que, por lo visto, pudieron surgir también determinadas actitudes [...]. Ver en semejante situación a un país que ha dado al mundo tantos misioneros, tantos santos, que se encuentra también en el origen de nuestra fe en Alemania y donde, hoy como ayer, sigue habiendo muchos buenos sacerdotes, es algo tremendamente estremecedor y oprimente. Sobre todo, naturalmente, para los católicos en la misma Irlanda, donde sigue habiendo muchos buenos sacerdotes [...]. Al respecto me comentó algo muy interesante el arzobispo de Dublín. Dijo que el derecho penal eclesial funcionó hasta los últimos años de la década de 1950, que si bien no había sido perfecto - mucho hay en ello para criticar- se lo aplicaba. Pero desde mediados de la década de 1960 dejó simplemente de aplicarse. Imperaba la conciencia de que la Iglesia no debía ser más Iglesia del derecho, sino Iglesia del amor, que no debía castigar. Así se perdió la conciencia de que el castigo puede ser un acto de amor"»; Benedicto XVI, Luz del mundo. El Papa, la Iglesia y los signos de los tiempos. Una conversación con Peter Seewald (Barcelona: Herder, 2010), 16. 
abusos de menores ${ }^{50}$. A los obispos, reunidos en Birmingham, el 19 de septiembre, el papa les habló del «vergonzoso abuso de niños y jóvenes por parte de sacerdotes y religiosos». Les recuerda las profundas heridas causadas por estos abusos, especialmente a las víctimas, pero también a las relaciones entre sacerdotes y obispos y la misma Iglesia y la gente. Y les invita a reparar por tales abusos, acercándose a todas las víctimas, mostrándose solidarios con cada una de ellas. Afirma el papa:

«Otro asunto que ha llamado mucho la atención en los últimos meses, y que socava gravemente la credibilidad moral de los Pastores de la Iglesia, es el vergonzoso abuso de niños y jóvenes por parte de sacerdotes y religiosos. He hablado en muchas ocasiones de las profundas heridas que causa dicho comportamiento, en primer lugar en las víctimas, pero también en las relaciones de confianza que deben existir entre los sacerdotes y el pueblo, entre los sacerdotes y sus obispos, y entre las autoridades de la Iglesia y la gente en general. Sé que habéis adoptado serias medidas para poner remedio a esta situación, para asegurar que los niños estén eficazmente protegidos contra los daños y para hacer frente de forma adecuada y transparente a las denuncias que se presenten. Habéis reconocido públicamente vuestro profundo pesar por lo ocurrido, y las formas, a menudo insuficientes, con que esto se abordó en el pasado. Vuestra creciente toma de con-

${ }^{50}$ El 18 de febrero de 2013 el papa Benedicto XVI aceptó la renuncia de mons. Keith O'Brien, cardenal arzobispo de Saint Andrews y Edimburgo. Había sido acusado por varios sacerdotes de comportamientos inapropiados en la década de los 80 . Posteriormente el 15 de mayo de 2013 el papa Francisco pidió al cardenal abandonar Escocia durante unos meses para llevar a cabo un periodo de renovación espiritual, oración y penitencia. El 20 de marzo de 2015, la Santa Sede hizo público el siguiente comunicado: «El Santo Padre — se lee en el comunicado vaticano- ha aceptado la renuncia a los derechos y a las prerrogativas del cardenalato, expresadas en los cánones 349, 353 y 356 del Código de Derecho Canónico, presentada, al final de un largo itinerario de oración, por su eminencia el señor cardenal Keith Patrick O’Brien, arzobispo emérito de Saint Andrews y Edimburgo. Con esta medida, Su Santidad manifiesta a todos los fieles de la Iglesia de Escocia su preocupación pastoral y los anima a continuar con confianza el camino de renovación y de reconciliación»; cfr. OPSS, Comunicato stampa. Este anuncio hace evidente cuál fue el resultado de la investigación llevada a cabo por la CDF y demuestra la veracidad de las acusaciones en contra del cardenal. Aunque la renuncia haya sido presentada formalmente por el mismo O'Brien, es probable que se haya tratado de una decisión acordada y de alguna manera solicitada por la misma Santa Sede. Con esta inédita decisión, se confirma la voluntad del papa Francisco de seguir por la valiente vía que emprendió su predecesor Benedicto XVI frente a este tipo de escándalos. 
ciencia del alcance del abuso de menores en la sociedad, sus efectos devastadores, y la necesidad de proporcionar un correcto apoyo a las víctimas debería servir de incentivo para compartir las lecciones que habéis aprendido con la comunidad en general. En efecto, ¿qué mejor manera podría haber de reparar estos pecados que acercarse, con un espíritu humilde de compasión, a los niños que siguen sufriendo abusos en otros lugares? Nuestro deber de cuidar a los jóvenes no exige $\operatorname{menos} »^{51}$.

El día antes, el papa se había manifestado con palabras semejantes en la catedral de Wetsminster y también en la St. Peter's Residence de Londres a un grupo de personas dedicadas a la protección de los niños ${ }^{52}$.

Ya durante el viaje, camino de Inglaterra, Benedicto XVI había indicado las prioridades a tener en cuenta en la atención a las víctimas y la persecución de este delito. Lo hizo con estas palabras:

«Me parece que ahora debemos llevar a cabo un tiempo de penitencia, un tiempo de humildad y renovar y volver a aprender con absoluta sinceridad. En cuanto a las víctimas, diría que son importantes tres cosas. El primer interés son las víctimas: ¿cómo podemos reparar? ¿Qué podemos hacer para ayudar a estas personas a superar este trauma, a reencontrar la vida, a reencontrar también la confianza en el mensaje de Cristo? Solicitud, compromiso por las víctimas, es la prioridad, con ayuda material, psicológica, espiritual. Segundo: el problema de las personas culpables. La pena justa es excluirlas de toda posibilidad de acceso a los jóvenes, porque sabemos que se trata de una enfermedad y la voluntad libre no funciona donde existe esta enfermedad. Por lo tanto, debemos proteger a estas personas de sí mismas y encontrar el modo de ayudarlas y de apartarlas de todo acceso a los jóvenes. El tercer punto es la prevención en la educación, en la elección de los candidatos al sacerdocio: estar tan atentos que, hasta donde es humanamente posible, se excluyan futuros casos» $»^{53}$.

Queda claro que el papa Benedicto XVI no solo habló del «vergonzoso abuso de niños y jóvenes por parte de sacerdotes y religiosos» sino que insistió, una vez más, en la necesidad de aplicar la normativa de la Iglesia, adoptar nuevas y serias medidas y trabajar por la reconciliación,

51 Benedicto XVI, "Discurso a los Obispos de Inglaterra, Gales y Escocia”, 2.

52 Cfr. "Saludo del santo Padre a un grupo de responsables", 3.

53 "Encuentro del Papa con los periodistas", 4. La prevención es uno de los puntos clave de la intervención decisiva del papa Benedicto XVI. 
la curación profunda y la necesaria paz de todas las víctimas. Una prueba más de ese desvelo del papa por afrontar sin miedo el escándalo de los abusos son las numerosas actuaciones disciplinares. Estas actuaciones afectaron indistintamente a cardenales, arzobispos, obispos, sacerdotes y fundadores ${ }^{54}$.

Recientemente el papa emérito Benedicto XVI ha sorprendido a la Iglesia con dos importantes aportaciones. Nos referimos, en primer lugar, a los «apuntes» que preparó con motivo del encuentro en Roma de los presidentes de las Conferencias Episcopales para tratar el doloroso tema de los abusos ${ }^{55}$. Posteriormente redactó una breve nota respondiendo a algunas críticas que habían generado esos "apuntes» ${ }^{56}$. Se trata de dos documentos singulares y significativos. El papa emérito no incide en los argumentos «comunes» para hablar de estos temas. Al contrario pone el acento en la ideología que se instala en la sociedad a partir de mayo del 1968, el grave debilitamiento de la fe, la crisis de la moral tradicional, el relativismo dominante y la ausencia de Dios $^{57}$.

Benedicto XVI no solo busca combatir el delito, sino que incorpora aspectos que, desgraciadamente, la Iglesia había olvidado o al menos atendido poco. Nos referimos a la tutela de las víctimas, la detección precoz del abusador y la necesaria sanación. Se acabó con Benedicto XVI la ocultación de estos delitos, el rechazo de las víctimas e incluso, en muchos casos, su humillación, el cuidado del «buen nombre» de la Iglesia, los «traslados» de sacerdotes abusadores. La Santa Sede, como hemos visto, pide incluso a las conferencias episcopales que legislen en

${ }^{54}$ En la tesis doctoral que en su día defendí en la Universidad Pontificia Comillas se encuentra un elenco de las principales actuaciones disciplinares del papa Benedicto XVI en esta materia. Sobresalen, de manera especial, las referentes al padre Marcial Maciel, fundador de los Legionarios de Cristo, y el padre Fernando Karadima, célebre sacerdote chileno.

55 Pueden consultarse, por ejemplo, en: https://www.aciprensa.com/noticias/ el-diagnostico-de-benedicto-xvi-sobre-la-iglesia-y-los-abusos-sexuales-35201. Visitado el 2 de septiembre de 2019.

${ }^{56}$ Se trata de una respuesta a la Prof. a B. Aschmann, Herder Korrespondenz 9 (2019): 51.

${ }^{57}$ La denuncia del relativismo instalado en la sociedad y también en la Iglesia no es un argumento nuevo en Benedicto XVI. Lo ha denunciado y precisado en numerosas ocasiones a lo largo de su ministerio; cfr. http://www.vatican.va/gpII/documents/homily-pro-eligendo-pontifice_20050418_sp.html (visitado el 2 de septiembre de 2019). 
esta materia y colaboren con la justicia civil, aunque pueda parecer un proceso difícil y complicado. Y algunas conferencias se muestran reticentes o presentan normas demasiado vagas o ineficaces. Todo ello prueba de las dificultades y contradicciones con las que se encuentra el papa. Con razón afirma Brunori que Ratzinger se encontró con «una guerra en la que ha luchado con determinación contra fuerzas hostiles, a veces en soledad $\aleph^{58}$. El mismo autor afirma que a partir de ahora la dirección a seguir

«[...] se ha fijado con claridad: con el giro que imprime Ratzinger - primero como cardenal y luego como pontífice, línea que ha mantenido y promovido el papa Francisco-, se puede decir que ninguna otra institución ha hecho tanto en la lucha contra los abusos sexuales a menores, fenómeno este que, por desgracia, afecta también a la familia, a la escuela, a las organizaciones deportivas y a las demás confesiones y religiones no cristianas $»^{59}$.

Así hay quien habla del «estilo Ratzinger» en la lucha contra la pedofília en la Iglesia. Un estilo que no la emprende contra los medios que publican noticias sobre los abusos, sino que valora el papel incómodo pero a la vez importante de los mismos. Así afirma Benedicto XVI:

«Los medios no podrían haber informado de esa manera si el mal no estuviese presente en la misma Iglesia. Solo porque el mal estaba en la Iglesia pudo ser utilizado por otros en su contra [...]. En la medida que es verdad, tenemos que estar agradecidos por toda información. La verdad, unida al amor bien entendido, es el valor número uno» ${ }^{60}$.

El papa Benedicto XVI no solo afronta el problema, sino que le pone solución. La normativa se endurece. También por primera vez se condena de modo explícito la manera en la que el problema era gestionado por quienes tenían autoridad: ni se evitaron, ni se atendieron, ni se sancionaron en muchos casos ${ }^{61}$.

Benedicto XVI permanece vigilante y además de sus intervenciones magisteriales, tiene gestos. Se encuentra, como hemos visto, en varias ocasiones con las víctimas, escucha sus sufrimientos, pide perdón y

58 Giovan Battista Brunori, Benedicto XVI (Madrid: Paulinas, 2018), 181.

59 Ibid., 191.

60 Benedicto XVI, Luz del mundo, 28.

${ }^{61}$ Benedicto XVI, Carta a los Católicos de Irlanda, 4. 
comparte con ellos las lágrimas ${ }^{62}$. Decía Benedicto XVI en su Carta a los católicos de Irlanda: "En varias ocasiones, desde mi elección a la Sede de Pedro, me he encontrado con víctimas de abusos sexuales y estoy dispuesto a seguir haciéndolo en futuro. He hablado con ellos, he escuchado sus historias, he constatado su sufrimiento, he rezado con ellos y por ellos ${ }^{63}$. Esa misma actitud es la que se pide a las diferentes Iglesias locales que responden con gestos similares y normativa abundante sobre la materia. Se elaboran protocolos de actuación por parte de episcopados nacionales, bajo el impulso y amparo de la Santa Sede. Y se impulsan congresos, simposios, encuentros sobre esta materia. Significativo fue el celebrado del 6 al 9 de febrero de 2012 en la Universidad Gregoriana de Roma, con la participación de obispos y expertos de todo el mundo ${ }^{64}$.

Sin embargo, nuestro estudio carecería de auténtico valor científico si no hiciéramos referencia a algunos aspectos del modo en que se ha ido elaborando la normativa que, a nuestro criterio, han influido en el resultado final y en la percepción de la opinión pública a nivel mundial. Hacemos referencia brevemente a estos cuatro aspectos: 1) la urgencia en su elaboración; 2) la fuerte presión mediática, a veces interesada y acentuada, por ejemplo, a lo largo del Año Sacerdotal ${ }^{65}$; 3) la respuesta «lenta» y «apagada» de algunas Iglesias locales; 4) la incomprensión o cierto «rechazo» de parte de la normativa por una sociedad civil que no entiende parte de la misma. Es cierto que la magnitud del escándalo provoca una reacción a veces poco acertada o precisa en la elaboración de la normativa. Hay que responder en poco tiempo y de manera contundente a escándalos que se manifiestan en lugares distintos y con especial virulencia. En muchos casos, como en EE. UU., bajo una presión judicial y amenazas de indemnizaciones millonarias. También es cierto que los medios de comunicación destapan innumerables acusaciones de abusos, a veces, con un cierto matiz de morbosidad y, en ocasiones, sin una investigación

${ }^{62}$ Cfr. "El Papa reza y llora con ocho víctimas de abusos sexuales en Malta", $A B C$, 19 de abril de 2010, visitado el 13 de mayo de 2018, http://www.abc.es/20100418/ sociedad-religion/papa-reune-ocho-victimas-201004181420.html

63 Benedicto XVI, Carta a los católicos de Irlanda, 5.

${ }^{64} \mathrm{Cfr}$. "El congreso contra la pederastia convocado por la Gregoriana no tiene precedentes", Religión en Libertad, 19 de junio de 2011, visitado el 13 de mayo de 2018, https:/www.religionenlibertad.com/el-congreso-contra-la-pederastia-convocado-por-la-gregoriana-no-tiene-16116.htm.

${ }_{65}$ Cfr. Benedicto XVI, Homilía del Santo Padre en la Fiesta del Sagrado Corazón de Jesús, 1. 
esmerada sobre la veracidad de los mismos. Hay intereses más allá de lo puramente informativo, con especial virulencia en momentos concretos que permiten ofrecer una mayor difusión de las noticias. Por último, ha faltado una política de comunicación eficaz y transparente. Aspectos muy positivos de la normativa no han sido bien presentados a la opinión pública que los ha recibido con un cierto rechazo. El secreto pontificio que afecta a algunos aspectos de la normativa sobre abusos, por ejemplo, no ha sido entendido como protección de la víctima sino como «reliquia» de antiguos procedimientos de silencio u ocultación. Todos estos aspectos merecen, a nuestro entender, un estudio más pormenorizado.

La actuación que emprende Joseph Ratzinger - primero como cardenal y luego como pontífice, línea que ha continuado el papa Francisco- es de tal magnitud que pocas o ninguna otra institución ha hecho tanto en la lucha contra los abusos a menores. También es cierto que si a ese esfuerzo no le acompaña la colaboración de las Iglesias locales e instituciones religiosas, será altamente loable en el papa pero sin a penas incidencia en el resto de la Iglesia ${ }^{66}$.

\section{ALGUNAS PROPUESTAS PARA LA REFLEXIÓN}

No es el objetivo de este estudio ofrecer únicamente un recorrido histórico de la normativa. Creo interesante ofrecer también unas reflexiones sobre algunos aspectos de la normativa actual. No son solo fruto del estudio sino también de la experiencia adquirida en estos últimos años. Podría detenerme también en otros aspectos, pero prefiero centrarme en este momento en algunos prioritarios que, a mi criterio, merecen una atención especial y, sin duda, una aplicación precisa, prudente y justa.

\subsection{EN RELACIÓN AL «TIPO PENAL» Y LA «PENA»: NECESIDAD DE UNIFICAR CRITERIOS Y ACTUACIONES}

La norma universal pone de manifiesto que el abuso sexual de un menor, como tipo penal, comprende una gran variedad de actos contrarios a sexto mandamiento y que no todos pueden y deben considerarse

\footnotetext{
${ }_{66}$ El papa Francisco ha dado un paso más en la lucha contra los abusos con el m. p. Vos estis lux mundi, del 9 de mayo de 2019. 
igualmente graves. Es necesario que la pena se adecúe a la gravedad del acto y que se proceda con prudencia en la imposición de las sanciones más graves y definitivas. Benedicto XVI ha buscado unificar criterios, pero también prontitud y respeto al derecho. Es necesario que lo universal aparezca claramente en la normativa particular, buscando garantizar derechos y ejercer la justicia rectamente. En la mayoría de las legislaciones estatales que hemos podido estudiar (EE. UU., Italia, Reino Unido, etc.) los delitos de abuso sexual y de pedopornografía afectan a los menores de 18 años. En cambio, la legislación canónica actual diferencia entre el delito de abuso sexual de menores de 18 años de edad y el de «pedopornografía» de menores de 14 años. ¿No sería bueno y deseable unificar criterios? Seamos prudentes y justos evitando crear una legislación business class para unos y economy class para los demás.

En este apartado quiero detenerme brevemente en un aspecto que considero merece una especial atención. Me refiero a la relación entre la así denominada «tolerancia cero» y la misericordia. Algunos han definido el esfuerzo del papa Benedicto XVI contra los abusos con la expresión «tolerancia cero». Sin embargo, conviene recordar, que esta expresión se incorpora ya a esta materia durante el pontificado de san Juan Pablo II. También se refieren a la misma durante el pontificado actual. La «tolerancia cero» resulta apropiada e imprescindible en aquellos casos donde quede demostrada la comisión de un delito y exista riesgo concreto de que se repita. Pero la Iglesia, en este caso la autoridad, ¿debe desentenderse del todo del sacerdote condenado? Para ello hay que acudir siempre al Evangelio que, no olvidemos, inspira el derecho de la Iglesia. El Señor es muy duro con aquellos que escandalizan a los pequeños, pero también pide perdonar siempre y buscar a la oveja perdida. Hay que ser «intolerantes» con el delito pero no olvidar nunca la misericordia. La cautela, la prudencia y una reflexión serena se imponen en esta materia.

San Juan Pablo II, al condenar rotundamente y alejar del sacerdocio y la vida religiosa a quienes abusan de niños, afirmaba a continuación: «Al mismo tiempo no podemos olvidar el poder de la conversión cristiana, la decisión radical de apartarse del pecado y de acercarse a Dios, que llega a las profundidades del alma humana y que puede obrar un cambio extraordinario ${ }^{67}$. Una cosa es impedir el ejercicio del sacerdocio (cosa más que evidente cuando además de cometido un delito hay peligro de

${ }^{67}$ Discurso a los cardenales norteamericanos, 2. 
reincidencia) y otra desentenderse del culpable que, en la mayoría de los casos, se encontrará posibilitado de cometer otros abusos, al margen de cualquier tipo de vigilancia. Con razón Dulles afirma: «La reducción de un sacerdote al estado laical no asegura la seguridad de los niños, cuya protección, se supone, es norma decisiva. Tal como ya hemos dicho, a menudo aparta al sacerdote de un entorno en el cual su conducta podría estar adecuadamente supervisada ${ }^{68}$. La Iglesia, junto al esfuerzo decidido por evitar el delito, no debería transmitir la idea de que no le importa el delincuente sexual o que lo considera más allá de toda redención. La exclusión y la demonización del agresor sexual no solo contradice el Evangelio, sino que aumenta la posibilidad de reincidencia.

\subsection{EN RELACIÓN CON ALGUNOS ASPECTOS DEL PROCEDIMIENTO}

Como hemos visto anteriormente, una muestra de la actuación eficaz de la Iglesia en la lucha contra los abusos está la posibilidad de actuar mediante el proceso administrativo penal. Este proceso penal extrajudicial es el indicado en la normativa para la remoción permanente y total cuando haya causas que dificulten la vía judicial. Es un proceso rápido, con evidentes diferencias en relación al proceso judicial, pero que a nuestro criterio debe respetar rigurosamente tres aspectos: la presunción de inocencia, el derecho de defensa y la tutela de la buena fama. Me pregunto junto a otros penalistas: ¿se respeta la presunción de inocencia hasta el pronunciamiento final?; ¿se ofrece desde el primer instante de la denuncia la debida y necesaria asistencia técnica al acusado?; ¿se garantiza la publicidad de las pruebas sin restricción, respetando evidentemente el secreto de oficio?; la no cercanía al órgano que juzga ¿ayuda al derecho de defensa? Son cuestiones que, a mi entender, están aún pendientes de resolver.

\subsection{EN RELACIÓN CON LA PRESCRIPCIÓN}

Buena parte de las denuncias que se han producido y siguen produciéndose obedecen a décadas anteriores. Son los llamados «delitos

${ }^{68}$ Avery Dulles, "Rights of accused priests: toward a revision of the Dallas charter and the Essential Norms", America 20 (2004): 4. 
históricos». A medida que la normativa se ha ido consolidando, han aumentado los plazos de prescripción, se ha añadido la posibilidad de la dispensa y se han modificado los criterios para proceder a la misma.

La prescripción garantiza a los miembros de la Iglesia la seguridad jurídica, es decir, la estabilidad de sus derechos. Toda situación conflictiva no puede quedar en suspenso permanentemente ${ }^{69}$. Sin embargo, las normas recientes sobre la prescripción «invitan» a una aplicación retroactiva de las mismas. No se aplican solo para delitos cometidos después de las normas, sino a delitos anteriores. Es evidente que Benedicto XVI endurece la normativa en este aspecto.

Prescindir de entrada de la prescripción me parece una temeridad y, si esta debe obviarse en algún caso, debe concretar y manifestar de manera clara los motivos, para no caer en la tragedia antijurídica de la arbitrariedad. El correr del tiempo no solo dificulta el conocimiento de la verdad, sino también la objetividad de la misma. La prescripción, sin embargo, no debe impedir la investigación ni la corrección oportuna, valorando todas las circunstancias que afecten a la denuncia.

\subsection{EN RELACIÓN CON LA PREVENCIÓN}

Son numerosas las intervenciones del papa emérito en este sentido. A través de sus actuaciones normativas, pastorales y disciplinares el papa marcó unas prioridades: cuidar de las víctimas, seleccionar bien a los candidatos al sacerdocio e impartir justicia a los culpables evitando cualquier reincidencia. Decía Benedicto XVI:

«Lo que nunca debe suceder es escabullirse y pretender no haber visto, dejando así que los autores de los crímenes sigan cometiendo sus acciones. Por tanto, es necesaria la vigilancia de la Iglesia, el castigo para quien ha faltado, y sobre todo la exclusión de todo ulterior acceso a niños. Como he dicho, lo que está primero es el amor a las víctimas, el esfuerzo por hacerles todo el bien posible a fin de ayudarlos a procesar lo que han vivido $»^{70}$.

Benedicto XVI nos ha enseñado que las víctimas de abuso sexual piden dos cosas a la Iglesia: una que la Iglesia diga «lo siento», otra que la

${ }^{69}$ Cfr. Astigueta, 49.

70 Benedicto XVI, Luz del mundo, 18. 
Iglesia diga «no pasará más». «Lo importante —afirma el Papa—es, en primer lugar, cuidar de las víctimas y hacer todo lo posible por ayudarles, y por estar a su lado con ánimo de contribuir a su sanación $»^{71}$. Se hacen necesarios los encuentros personales (víctima-autoridad) iniciados y fomentados por Benedicto XVI y la colaboración multidisciplinar, como aparece, por ejemplo, en la normativa de numerosas diócesis norteamericanas. Los encuentros con las víctimas pueden constituir desafíos para todos los involucrados, pero también pueden ser una instancia de gracia, de perdón y de entendimiento.

Benedicto XVI pide una «selección correcta» de los candidatos al sacerdocio. Me detengo aquí brevemente en un aspecto que hay que tener en cuenta. Me refiero a la denominada «angustia vocacional»: la situación de grave escasez vocacional en numerosas iglesias particulares e institutos religiosos. La «angustia vocacional» conlleva, en muchos lugares y ámbitos, una pobreza de la propuesta formativa: se normaliza la mediocridad y el discernimiento se vuelve superficial ${ }^{72}$. Se atenúa el rigor en la propuesta vocacional, se reduce su importancia y exigencias, se facilita el camino evitando el conflicto, se «discierne» superficialmente atentos únicamente a las formas, se confunde el bien aparente y el bien real del aspirante. Se falta a la verdad. ¡Cuántas veces en la historia vocacional de quien ha cometido abusos sexuales se encuentran discernimientos de este tipo! La «angustia vocacional» suscita vocaciones discretamente angustiadas y angustiantes.

\subsection{EN RELACIÓN CON LA COMUNICACIÓN A LA AUTORIDAD CIVIL}

Es un tema muy actual y, en cierto modo, polémico. No debe rehuirse en el estudio ni en el debate. La carta circular, ya mencionada, recuerda la necesidad de colaborar con la autoridad civil. Cualquier actuación debe tener en cuenta que el abuso sexual de menores no es solo un delito canónico, sino también un crimen perseguido por la justicia civil. Y que hay que evitar dos tendencias contrapuestas pero frecuentes: la de resolver ad intra este tipo de situaciones al margen de la colaboración civil y la de «entregarse» $\mathrm{o}$ «sujetarse» únicamente a la autoridad civil como si la Iglesia no tuviera nada que decir y hacer en esa materia.

${ }^{71}$ Luz del mundo, 22.

${ }^{72}$ Cfr. Amadeo Cencini, ¿Ha cambiado algo en la Iglesia después de los escándalos sexuales? (Salamanca: Sígueme, 2016), 150. 
La necesaria transparencia en la gestión de los abusos no contradice la indispensable prudencia a la hora de abordar estos asuntos. Esa prudencia debe ejercerse especialmente a la hora de facilitar la información a los medios, respetando especialmente el derecho a la intimidad de la víctima y también la presunción de inocencia de los implicados. Afirma R. Medina: «Hay que recordar que toda intervención pública del Obispo o Superior debe ser prudente, pues la presunción no implica que el acusado ya sea culpable. De hecho, los indicios sobre los que se ha basado podrían ser falsos, y cualquier intervención por parte del Obispo o Superior podría interpretarse por la gente como que el hecho ha ocurrido realmente, cuando aún no se sabe con certeza, y, por ello, podría ser lesiva para la buena fama del clérigo ${ }^{73}$. Por consiguiente, el obispo o superior religioso deberá ser especialmente prudente a la hora de tomar, si procede, las medidas cautelares, evitando dar la impresión que los hechos han sido ya verificados y, por tanto, son ciertos. También las actuaciones que pueda realizar el obispo o superior religioso, mientras se investigan los hechos, deberán evitar aumentar el dolor de las víctimas o lesionar la presunción de inocencia del acusado ${ }^{74}$. Comparto plenamente la preocupación de E. Bianchi cuando afirma

«No oculto que desearía una mayor prudencia, también por parte de los católicos, al emitir juicios generalizados: no para cubrir el mal, sino para que se evite culpabilizar a iglesias nacionales enteras como si en su conjunto fueran peores que otras. Una mayor discreción por parte de todos favorecería la asunción de la responsabilidad por parte de las iglesias locales en el gobierno y la gestión - con el respeto a los procedimientos jurídicos y la preocupación primaria por las víctimasde estas situaciones dramáticas en la verdad, en la justicia y en la misericordia, que no debe faltar nunca, ni siquiera en casos extremos» ${ }^{75}$.

${ }^{73}$ Ricardo Daniel Medina, "Imputabilidad, eximentes, atenuantes y agravantes en los delitos sexuales de clérigos con menores (I)", Anuario Argentino de Derecho Canónico 19 (2013): 142.

${ }^{74}$ Nos preguntamos hasta qué punto procede llevar a cabo un acto de petición de perdón por unos hechos que acaban de ser denunciados y están en proceso de verificación. Otra cosa sería una petición general por los abusos cometidos por miembros de la Iglesia.

75 "Pedofili, l'umiliazione evangelica", La Stampa, 14 de marzo de 2003, visitado el 3 de mayo de 2018, http://archivio.lastampa.it/m/articolo?id=9840545941d93a35277 a4c4559c3c072d6368b9a 
Se podría recuperar la confianza mediante una aplicación pública, transparente y coherente de los reglamentos legales vigentes en la Iglesia católica. Esto permitiría también a la Iglesia realizar de nuevo totalmente su encargo de proclamar el Evangelio de Jesucristo en la sociedad con plena credibilidad.

\subsection{EN RELACIÓN AL DENOMINADO «ABUSO DE PODER»}

Es importante insistir, al referirse al abuso sexual por parte de clérigos, en la relación que se establece entre el abusador clérigo y la víctima. Es siempre una superioridad que se impone a la debilidad, una confianza que se convierte en traición. Como afirmo al inicio de este artículo, el clérigo abusador busca humillar, es más ensañarse en el otro, mediante una utilización tergiversada y maligna de la sexualidad. Ese fenómeno de poder supone una tragedia pues no solo impone su voluntad en el otro, sino que priva de la libertad al que sufre el abuso, lo violenta, lo utiliza, lo degrada y lo anula. En estos casos, el clérigo no solo abusa sino que posteriormente engaña y procura revestir de legitimidad los actos que ha realizado. $\mathrm{Al}$ abuso le sucede, en la mayoría de las ocasiones, un engaño que se mantiene en silencio a veces por años, bajo el poder, la superioridad que encarna el sacerdote.

El abuso de poder no se circunscribe únicamente al ámbito sexual. En ocasiones, como hemos podido comprobar, se introduce en la conciencia del otro y lo violenta, influye en sus decisiones más íntimas, corrompe su libre capacidad de elección y produce no un hombre libre, sino un autómata que se mueve bajo la decisión de otro. Este tipo de abuso de poder reviste una especial gravedad en la Iglesia y, a mi criterio, sucederá al abuso sexual con el mismo o mayor escándalo. Hay que atender especialmente este fenómeno en la Iglesia.

\section{A MODO DE CONCLUSIÓN}

Quisiera acabar con una breve reflexión final fruto de la gestión personal de los abusos y del trato con las víctimas. La mayoría de las víctimas que han sufrido abusos son gente perteneciente a movimientos de Iglesia, educativos o grupos parroquiales. Al enorme dolor causado por 
el abuso sufrido, se unía el dolor porque estos hechos hubieran tenido lugar en el ámbito de la Iglesia. Y, además, muchas víctimas denunciaban no tanto buscando una condena y un resarcimiento, sino para evitar que esos hechos se pudieran repetir. Para ellos era incomprensible que personas que decían amar a Dios, que se presentaban como ministros de la misericordia, se hubieran convertido en causantes de tanta ignominia. La Iglesia ha reflexionado y ha pedido perdón; pero ahora se trata de aplicar la ley, priorizando aquellos aspectos que son más básicos y que a nuestro entender deberían insistir en la prevención, la formación, la aplicación de la ley y la sanación o reparación. El olvido de estos aspectos básicos o su dejadez no solo causan daño a la Iglesia, sino escándalo e incomprensión ante la Iglesia y una sociedad cada vez más plural y exigente.

La Iglesia ha elaborado la normativa reciente en medio de una gran presión no solo mediática, sino también ambiental. La sociedad, el mismo Pueblo de Dios, ha exigido una respuesta. Se hace necesario, sin embargo, una mayor produndización en las causas de los abusos. Benedicto XVI apuntaba ya alguna de esas causas en la carta que dirigió a los católicos de Irlanda. Me refiero evidentemente a causas internas que hay que buscar dentro de la Iglesia. Entre estas hay que prestar una especial atención al grave debilitamiento de la vida de la gracia, la selección, preparación y formación de los candidatos al sacerdocio y a la vida religiosa y la siempre presente tentación de «adecuarse» al pensamiento moderno.

Detrás de los abusos (y de su mala gestión en ocasiones) hay mucho sufrimiento, muchas víctimas. No puede abordarse esta temática sin sentir empatía con quienes han sufrido. Y también con aquellos que, en la Iglesia, se han esforzado por crear un marco jurídico adecuado que permita afrontar con pericia y en justicia este delito. Entre estas personas, evidentemente, sobresale de manera especial el papa Benedicto XVI. Como afirmo al inicio de mi contribución, en palabras del papa Francisco, él fue la "puerta» que permitió emprender este camino. Nuestro trabajo manifiesta suficientemente su gran aportación. Pero el tiempo aún lo hará más evidente. Mientras esperamos ese mayor reconocimiento, no dejemos de aplicar todo cuánto él nos ha enseñado. 


\section{REFERENCIAS}

\section{Fuentes}

Benedicto XVI. "Carta a los católicos de Irlanda". La Santa Sede. 19 de marzo de 2010. Consultado el 2 de mayo de 2018. http://w2.vatican.va/content/benedict-xvi/es/letters/2010/documents/hf_ben-xvi_ let_20100319_church-ireland.html

Benedicto XVI. “Discurso a los Obispos de Inglaterra, Gales y Escocia”. La Santa Sede. 19 de septiembre de 2010. Consultado el 2 de mayo de 2018. http://w2.vatican.va/content/benedict-xvi/es/speeches/2010/ september/documents/hf_ben-xvi_spe_20100919_vescovi-inghilterra. html

Benedicto XVI. "Saludo del Santo Padre a un grupo de responsables de la protección de los niños". La Santa Sede. 18 de septiembre de 2010. Consultado el 2 de mayo de 2018. https://w2.vatican.va/content/benedict-xvi/es/speeches/2010/september/documents/hf_benxvi_spe_20100918_st-peter-residence.pdf

Benedicto XVI. "Homilía del Santo Padre en la Fiesta del Sagrado Corazón de Jesús". La Santa Sede. 11 de junio de 2010. Consultado el 2 de mayo de 2018. http://w2.vatican.va/content/benedict-xvi/es/ homilies/2010/documents/hf_ben-xvi_hom_20100611_concl-anno-sac.html

Benedicto XVI. Luz del mundo. El Papa, la Iglesia y los signos de los tiempos. Una conversación con Peter Seewald. Barcelona, 2010.

Francisco. "Conferencia de Prensa del Santo Padre durante el vuelo de regreso a Roma". La Santa Sede. 17 de febrero de 2016. Consultado el 2 de mayo de 2018. https:/w2.vatican.va/content/francesco/es/ speeches/2016/february/documents/papa-francesco_20160217_messico-conferenza-stampa.html

Juan Pablo II. "Discurso a los Cardenales de EE. UU.". Ecclesia 14 (2002): 652-654.

Juan Pablo II. "Exhortación apostólica Pastores gregis". Conferencia Episcopal. Consultado el 8 de septiembre de 2019. https://www.conferenciaepiscopal.es/documentos/magisteriojpii/exhortacion/pastores2.htm\#5 


\section{Autores}

Arrieta, Juan Ignacio. "El proyecto de revisión del libro VI del Código de Derecho Canónico". Anuario de Derecho Canónico (2013): 211-231.

- "L'influsso del cardinale Ratzinger nella revisione del sistema penale canonico". La Civiltà Cattolica 3851 (2010): 430-440.

Astigueta, Damián. "La persona y sus derechos en las normas sobre abusos sexuales". Anuario de Derecho Canónico (2004): 11-56.

Aznar Gil, Federico R. "Abusos sexuales a menores cometidos por clérigos y religiosos". REDC 167 (2010): 827-850.

-. "La expulsión del estado clerical por procedimiento administrativo". REDC 168 (2010): 255-294.

Brockhaus, Ulrike, y Maren Kolshorn. "Die Ursachen sexueller Gewalt". En Sexueller MiBrauch. Überblick zu Forschung. Beratung und Therapie, dirigido por Gabriele Amann y Rudolf Wipplinger, 89-105. Tubinga, 1998.

Brunori, Giovanni Battista. Benedicto XVI. Madrid: Paulinas, 2018.

Cencini, Amadeo. ¿Ha cambiado algo en la Iglesia después de los escándalos sexuales? Salamanca: Sígueme, 2016.

Cito, Davide. "Las nuevas normas sobre los delicta graviora". Ius Canonicum 50 (2010): 643-658.

Dulles, Avery. "Rights of accused priests: toward a revision of the Dallas charter and the Essential Norms". America 20 (2004): 1-8.

Golab, Marek. "Facultades especiales para la dimisión del estado clerical (Congregación para el Clero de 30 de enero de 2009). Análisis y comentario". Ius Canonicum 50 (2010): 671-683.

Guth, Hans-Jürgen. "El abuso sexual como delito en el derecho canónico. Informe para una aplicación coherente de las normas jurídicas actualmente vigentes en la Iglesia Católica". Concilium 306 (2004): 125-137.

Levada, William. "El abuso sexual contra menores: una respuesta polifacética al reto". En Abuso sexual contra menores, dirigido por Charles Scicluna, Hans Zollner y Daniel Ayotte, 25-36. Santander: Sal Terrae, 2012.

Lombardi, Federico. "Nota sulla lettera circolare della Congregazione per la Dottrina della Fede alle Conferenze Episcopali". La Civiltà Cattolica 3864 (2011): 594-597. 
Martens, Kurt. "Les délits les plus graves réservés à la Congrégation pour la Doctrina de la Foi". Revue de Droit Canonique 56 (2006): 201-221.

Medina, Ricardo Daniel. "Imputabilidad, eximentes, atenuantes y agravantes en los delitos sexuales de clérigos con menores". Anuario Argentino de Derecho Canónico 19 (2013): 105-151.

Mosca, V. "Le facoltà speciali concesse alla Congregazione per l'Evangelizzazione dei Popoli e alla Congregazione per il Clero (in particolare circa la dimissione dalla condizione giuridica clericale in poenam ed ex officio per via amministrativa)". Quaderni de ius missionale 3 (2014): 159-180.

Nason-Clark N., y L. Ruff. “¿A qué llamamos violencia sexual?”. Concilium 306 (2004): 363-373.

Pardo, J. M. "Abuso a menores. Causas y posibles soluciones". Scripta Theologica 43 (2011): 297-321.

Politi, Marco. Joseph Ratzinger: crisi di un papato. Roma: Editori Laterza, 2013.

Robinson, G. Poder y sexualidad en la Iglesia. Santander: Sal Terrae, 2008.

Sánchez-Girón, José Luis. "Delitos contemplados en las normas De gravioribus delictis del año 2010”. Estudios Eclesiásticos 85 (2010): 731-767. 